\title{
Relação entre condição funcional docente e a percepção das condições de trabalho
}

\author{
Anoel Fernandes \\ PUC - SP \\ Edson Segamarchi dos Santos \\ Universidade Federal de Sorocaba
}

\section{Resumo}

Buscou-se verificar se a condição funcional de um grupo de professoras atuantes no ciclo I do ensino fundamental da rede pública estadual paulista interfere na percepção que possuem das condições de trabalho. Como procedimento de pesquisa, aplicou-se um questionário a 37 professoras, das quais três são estáveis, oito efetivas e 26 Ocupantes de Função Atividade (OFA), isto é, sem estabilidade no emprego. A análise dos dados foi pautada no conceito marxista de alienação e seus desdobramentos teóricos, desenvolvidos pelos autores da teoria crítica da sociedade, especialmente Adorno e Marcuse. Os dados demonstraram que as professoras OFA tendem a apresentar maior conformidade com o disposto.

Palavras-chave: Trabalho docente. Condição funcional. Teoria crítica. 


\section{Relationship between teaching functional condition and the perception of working conditions}

This study aims to verify whether the functional condition of a group of active female teachers in the first cycle of Primary Education of Sao Paulo state's public school system interferes in the perception they have of their working conditions. As a research procedure, it was applied a questionnaire to 37 teachers, among them three stable teachers, eight effective teachers and 26 Occupant of Activity Function, no job security. In order to analyze the data, this study was based on the Marxist concept of alienation and its theoretical developments made by the authors of the critical theory of society, especially Adorno and Marcuse. These data demonstrated that the OFA teachers tend to have higher conforming feelings, what is formalized on the opinions with lower criticality.

Keywords: Teacher's labor. Functional conditions. Critical theory.

\section{Relación entre la condición funcional de la enseñanza y la percepción de las condiciones de trabajo}

Hemos tratado de determinar si la condición funcional de un grupo de profesores activos en el primer ciclo de la educación básica de las escuelas públicas del estado interfiere con la percepción de que hayan condiciones de trabajo. Como procedimiento de investigación se aplicó un cuestionario a 37 docentes, tres estables, eficaces Función ocho y 26 Ocupantes Actividad (OFA), es decir, sin seguridad en el empleo. Para analizar los datos, se basa en el concepto marxista de alienación y de sus desarrollos teóricos desarrollados por los autores de la teoría crítica de la sociedad, en especial Adorno y Marcuse. Los datos mostraron que los profesores OFA tienden a tener mayor cumplimiento de las disposiciones.

Palabrasclave: enseñanza. condición funcional. lateoría crítica. 


\section{Introdução}

Parece ser consenso em discursos acadêmicos, no jargão popular ou até mesmo entre os corredores da escola, de que a função da educação atualmente perpassa as paredes de sala de aula. Não obstante, quando qualquer problema não consegue ser resolvido pela sociedade (seja ele preconceito, degradação do meio ambiente, gravidez na adolescência, violência no trânsito, dentre inúmeros outros), tão logo o tema em questão é designado para que a escola se aproprie dele. Dessa forma, a função da escola, que outrora era de ensinar determinados conteúdos - definidos, sobretudo, pela herança cultural e científica dos povos ao longo da história -, atualmente responde a uma infinidade de demandas sociais.

Como analogia, pode-se comparar a escola atual a um caminhão velho que já não suporta mais a carga e ainda tem de subir uma serra. Além disso, tem que parar constantemente para refrigerar o motor e, a cada parada, colocam mais um pouco de carga na carroceria. A escola atual parece estar na mesma situação do referido caminhão, ou seja, tal instituição está em sinal de alerta quanto à sua qualidade, mas, mesmo assim, novas demandas surgem constantemente para que apresente respostas que dela se espera.

Diante de tal situação, os professores, como representantes diretos da instituição escolar, acabam se tornando os principais responsáveis em "carregar" o fardo extra que frequentemente lhes é impingido. E é justamente nesse contexto que o trabalho docente ganha um significado particular, pois o exercício da docência, na atualidade, é definido de forma ampla, abrangendo não apenas a sala de aula ou o processo de ensino formal, mas todas as outras atividades inerentes à educação. A particularidade do trabalho docente reside justamente naquilo que é apontado por Barboza (2011) : diferentemente da maioria das demais profissões, o exercício da docência não se esgota quando soa o sinal da escola, anunciando a última aula do dia, uma vez que, para que se exerça uma prática docente comprometida e de qualidade, são necessárias várias horas de trabalho extraclasse com vistas a preparar aulas, corrigir atividades e provas dos alunos, realizar estudos que embasem as aulas, atender pais e alunos, dentre outras atividades.

Conforme Oliveira (2004), durante muitos anos o trabalho do professor era compreendido como tarefa destinada ao ensino, mas atualmente reconhece-se que extrapola essa função, uma vez que passaram a serem exigidas dos professores outras tarefas que não somente as de sala de aula propriamente dita. Pondera a autora que

O trabalho docente não é definido mais apenas como atividade em sala de aula, ele agora compreende a gestão da escola no que se refere à dedicação dos professores ao planejamento, à elaboração de projetos, à discussão coletiva do currículo e da avaliação. O trabalho docente amplia o seu âmbito e compreensão e, consequentemente, as análises a seu respeito tendem a se complexificar. (Oliveira, 2004, p. 1132) 
Se, na atualidade, o trabalho docente abrange essa complexidade de funções, cabe refletir sobre as determinações "do" e "pelo" trabalho às quais os professores são submetidos. Em outros termos, é necessária a dialética imanente entre o indivíduo e o trabalho. No entanto, antes de adentrar especificamente na discussão sobre condições de trabalho docente, apresenta-se a seguir algumas considerações acerca do trabalho, tendo como referência o conceito de alienação tal como desenvolvido por Marx , assim como as análises de Adorno e Marcuse do trabalho no capitalismo do século $X X$.

\section{Trabalho e alienação}

O conceito de alienação foi desenvolvido por Marx particularmente no interior de duas obras: Os "Manuscritos Econômico-Filosóficos" (1844) e "Elementos para a Crítica da Economia Política" (1857-58). Nos Manuscritos se desenrola o primeiro confronto de Marx com a Economia Política e é explorada, pela primeira vez, a ideia da alienação do trabalho e suas consequentes determinações em todas as esferas da vida social. Conforme Sánchez Vásquez (1977, p. 414-16), "quando Marx vai à realidade histórica social, só se vê essa essência - ao contrário de Hegel - por seu lado negativo. O trabalho que ele encontra na existência real, concreta do homem é justamente o trabalho alienado". Marx contrapõe-se a Hegel no que diz respeito ao esquema formativo elaborado a partir do "trabalho que forma", ou seja, a crítica de Marx está justamente no uso positivo da formação pelo trabalho, tal como defendida por Hegel. Ao se contrapor à perspectiva hegeliana, Marx realiza a análise do trabalho alienado. Com base nessa primeira aproximação ao tema, primeiramente é apresentada a concepção de trabalho, para, em seguida, discorrer sobre a alienação. Também é destacada a posição dos autores frankfurtianos sobre a questão.

Ao analisarem o sentido do trabalho, Marx e Engels (1994, p.15) afirmam que:

Podemos distinguir os homens dos animais pela consciência, pela religião, por tudo o que se quiser. Mas eles começam a distinguir-se dos animais assim que começam a produzir os seus meios de vida, passo este que é condicionado pela sua organização física. Ao produzirem indiretamente a sua própria vida material.

No entanto, sem levar em conta a dialética contida no trabalho, sua definição estaria incompleta. De um lado, é pelo trabalho que o homem se diferencia dos animais e, de outro, esse mesmo trabalho leva à perda de si: "chega-se à conclusão de que o homem (o trabalhador) só se sente livremente ativo nas suas funções animais comer, beber e procriar, quando muito, na habitação, no adorno etc. - enquanto nas funções humanas se vê reduzido a animal" (Marx, 2006, p. 114-15). 
Marx (2006) enfatiza que a existência do homem não é dada pela natureza, mas produzida pelos próprios homens. Portanto, diferentemente dos outros animais, que para garantirem a existência dependem exclusivamente da adaptação à natureza, o homem precisa fazer o contrário, isto é, precisa agir sobre a natureza com a finalidade de transformá-la, ajustando-a de acordo com suas necessidades, uma vez que, ao invés de somente adaptar-se à natureza, tem que adaptá-la a si. E é justamente esse agir sobre a natureza para garantir a sobrevivência que o autor define como trabalho.

É fato que em torno do conceito de trabalho enunciado por Marx existe muita discussão, a partir da qual se disseminam correntes - principalmente na sociologia do trabalho - que defendem ou não concordam com os postulados do autor. Entretanto, o que se apreende é que este continua sendo uma das bases da organização social. Resende $(2007$, p. 36$)$ recorre ao conceito marxista de trabalho como fundamental para o entendimento de como se constitui o processo de objetivação humana, enfatizando que "o trabalho é categoria fundamental na constituição do homem enquanto ser social (...)", uma vez que "é pelo trabalho que o homem se converte de ente da natureza em ser social. Por meio dele, pode-se chegar, então, àquela que é a 'chave' para a compreensão dialética da relação entre indivíduo e sociedade" (idem, p.37). Ao referir-se sobre o processo de trabalho, Marx (1983) o define como:

(...) atividade orientada a um fim para produzir valores de uso, apropriação do natural para satisfazer as necessidades humanas, condição universal do metabolismo entre o homem e a Natureza, condição natural eterna da vida humana e, portanto, independente de qualquer forma dessa vida, sendo antes igualmente comum a todas as suas formas sociais. (Marx, 1983, p. 153)

Destaque-se o fato de que suas proposições teóricas contribuem para a reflexão e análise do trabalho na sociedade atual. Crochík (2003, p. 70), ao mencionar em que consiste o trabalho, aponta que "na sociedade atual, o trabalho é defendido por tendências conservadoras e por tendências progressistas". Se o trabalho é defendido por ambas as tendências, assim como é a "chave" para a compreensão da dialética entre indivíduo e sociedade, tomá-lo como referência para a compreensão da objetividade e da subjetividade humana torna-se imprescindível, o que, por conseguinte, remete também para a reflexão sobre o trabalho e suas implicações, entre as quais, o processo de alienação. Ao definir a alienação por meio trabalho, Marx (2006, p. 114) assinala:

Em primeiro lugar, o trabalho é exterior ao trabalhador, ou seja, não pertence à sua característica; portanto, ele não se afirma no trabalho, mas nega-se a si mesmo, não se sente bem, mais, infeliz, não desenvolve livremente as energias físicas e mentais, mas esgota-se fisicamente e arruína o espírito. Por conseguinte, o trabalhador só se sente em si fora do trabalho, enquanto no trabalho se sente fora de si. Assim, o seu trabalho não é voluntário, mas imposto, é trabalho forçado. Não constitui a satisfação de uma necessidade, mas apenas um meio de satisfazer outras necessidades. (grifos do autor) 
As ponderações de Marx trazem à tona o fato de o trabalhador negar-se a si mesmo diante do trabalho e, dessa forma, entende-se que a alienação o atinge tanto internamente (sua psique), quanto externamente, na medida em que o produto de seu trabalho é apropriado pelo outro (empregador). Diante dessa constatação apontada pelo autor, pode-se postular que o trabalhador torna-se alguém possuidor de conhecimento restrito de suas funções, passando, então, simplesmente a executar tarefas e a reproduzir, sem condições de questionar, pois, o trabalho é uma necessidade que tem em sua base o atendimento de suas necessidades básicas, isto é, a subsistência humana.

Tendo em vista o fato de que as condições de trabalho levam os indivíduos às determinações acima apontadas, destaca-se a relevância de investigar como essa situação se materializa nas condições objetivas de trabalho dos professores, ou seja, como a alienação se realiza na profissão docente. Tal tarefa é necessária visto que se parte do pressuposto de que a alienação no trabalho traz implicações e ocasiona desdobramentos na vida cultural e social dos indivíduos. Portanto, na condição de alienado, o trabalhador se conforma às situações subjacentes a seu trabalho. Dessa forma, procura-se analisar as condições de trabalho docente ante as contradições da sociedade contemporânea que, como sociedade burguesa e capitalista, produz a alienação. Marx (2006), ao apontar no que consiste a alienação do trabalhador nas leis da Economia Política, afirma:

O trabalhador torna-se tanto mais pobre quanto mais riqueza produz, quanto mais a sua produção aumenta em poder e extensão. $O$ trabalhador torna-se uma mercadoria quanto mais barata, quanto maior número de bens produz. Com a valorização do mundo das coisas, aumenta em proporção direta a desvalorização do mundo dos homens (Marx, 2006, p. 111).

Essas considerações sobre trabalho alienado são retomadas por Adorno. Para ele:

Os homens seguem o que, segundo análise de Marx, eles eram por volta do século XIX: apêndices da maquinaria, e não mais apenas literalmente os trabalhadores, que tem de se conformar com as características das máquinas, mas além deles, muito mais metaforicamente: obrigados até em suas mais íntimas emoções a se submeterem ao mecanismo social como portadores de papéis, tendo de se modelar sem reservas de acordo com ele. Hoje como antes se produz visando o lucro. (Adorno, 1986, p. 68)

Ao discutir as necessidades e faculdades dos indivíduos e sua relação com o sistema capitalista, Marcuse (1969, p. 58) enfatiza que "os homens não vivem sua própria vida, mas desempenham tão só funções preestabelecidas. Enquanto trabalham não satisfazem somente suas necessidades e faculdades, mas trabalham em alienação". Apresentando uma discussão sobre a relação entre o trabalho e a civilização, Marcuse (1967, p. 88) enfatiza que "o trabalho que criou e ampliou a base material da civilização, foi principalmente labuta, trabalho alienado, penoso, desagradável - 
e ainda é". Seguindo esta linha de reflexão, sobre a alienação no trabalho, o autor ainda afirma:

A teoria de alienação demonstrou o fato de que o homem não se realiza em seu trabalho, que a sua vida se tornou um instrumento de trabalho, que o seu trabalho e os respectivos produtos assumiram uma forma e um poder independentes dele como indivíduo. Mas a emancipação desse estado parece requerer não que se impeça a alienação, mas que esta se consuma. (Marcuse, 1967, p. 103)

Com base nas afirmações de Marx, feitas em relação ao século XIX, e as análises de Adorno e Marcuse do capitalismo no século XX, pode-se concluir que o trabalho na sociedade atual continua sendo trabalho alienado. Mesmo com as profundas mudanças ocorridas na sociedade e do avanço tecnológico que as sustentam, tais mudanças não promoveram o fim do trabalho alienado, mas aprofundaram ainda mais o controle e dominação sobre o trabalhador. Sobre a relação entre o trabalho e o advento da tecnologia, Crochík (2004, p. 27) atesta

(...) o trabalho gira em falso. $O$ trabalho alienado, do qual já se poderia prescindir, tornase imprescindível; a tecnologia que deveria libertar, aprisiona, e como a contradição é cada vez mais visível, a descrença é inevitável, contudo, quanto menos há fé, mais ela se torna necessária, e o indivíduo subjuga-se ao que é contrário aos seus interesses mais racionais.

Assim, mesmo com todas as mudanças que tiveram como justificativa melhorar a vida do homem, permaneceu o aprisionamento, ou seja, as modificações tecnológicas e estruturais da sociedade não alteraram a natureza do trabalho na sociedade capitalista, assentado na alienação. Se esta atinge todos os trabalhadores, postulase que estes têm diminuídas as suas capacidades de reflexão e, por conseguinte, não têm consciência e controle sobre suas ações. Conforme Horkheimer e Adorno (1985, p. 47), as condições de trabalho forçam os indivíduos "ao conformismo e não às influências conscientes". Se as condições de trabalho conduzem os indivíduos à impossibilidade de reflexão, assim como ao conformismo, pode-se inferir que a tais condições também são submetidos os trabalhadores da educação.

\section{As condições de trabalho e suas implicações para a docência}

No presente tópico, serão desenvolvidas algumas ponderações sobre o trabalho, bem como suas implicações para os indivíduos que exercem a docência. Maar (2006), no texto "A centralidade da dialética do trabalho", enfatiza que: 
O sentido da questão da centralidade do trabalho está em sua relação com a sociedade. Por mais que haja consciência das condições que, pela centralidade do trabalho na formação social vigente, alienam os homens do próprio processo de trabalho, subordinando-os ao mesmo em vez de possibilitar que, por seu intermédio, se formem enquanto sujeitos. (Maar, 2006, p.26)

Por sua vez, Crochík (2003, p.5), ao discutir a relação entre liberdade e trabalho afirma que "é no tempo livre do trabalho que a possibilidade de liberdade ocorre, mas é o trabalho que a permite. A liberdade, assim, encontra-se fora do mundo do trabalho". Freud (2010), ao discorrer sobre a atividade profissional, trabalho e felicidade, enfatiza que:

O trabalho não é muito apropriado como via para a felicidade. As pessoas não se lançam a ele como a outras possibilidades de gratificação. A imensa maioria dos homens trabalha apenas forçados pela necessidade, e graves problemas sociais derivam dessa aversão humana ao trabalho. (Freud, 2010, p.36).

Seguindo essa linha de raciocínio, Marcuse (1969 p. 60), ao discutir o conflito entre princípio do prazer e da realidade, aponta que o "conflito irreconciliável não é entre o princípio do trabalho (princípio da realidade) e Eros (princípio de prazer), mas entre o trabalho alienado (princípio de desempenho) e Eros". Se o desempenho é o fundamento básico da alienação, o controle ao qual o indivíduo é submetido excede o âmbito somente do trabalho propriamente dito; vai além, chegando à própria vida privada do indivíduo, tal como enfatizado por Marcuse (1969, p.60):

(...) o controle básico do tempo de ócio é realizado pela própria duração do tempo de trabalho, pela rotina fatigante e mecânica do trabalho alienado, o que requer que o lazer seja um relaxamento passivo e uma recuperação de energias para o trabalho.

Sendo o trabalho definido nestes termos, Crochík (2003, p.72), após discutir suas variadas formas na sociedade atual e sua relação com o tempo livre, defende a tese de que "o tempo livre deveria ser utilizado como crítica e contraposição ao trabalho, como momento de tomar consciência da prisão existente", e não para fortalecer a alienação por meio de atividades voltadas à retomada do próprio trabalho.

Em geral, a alienação dos trabalhadores no tempo destinado ao exercício do trabalho propriamente dito traz sérias implicações para esses sujeitos, como se discutiu anteriormente, e em especial para a profissão docente, visto que há um consenso entre os dirigentes da educação e estudiosos em torno da excessiva sobrecarga de trabalho atribuída aos professores nos dias atuais, que se soma à imperiosa necessidade de se envolver em programas de formação continuada, visando não só aprimorar conhecimentos, mas também acrescentar ganhos pecuniários à carreira. Ora, diante disso é preciso perguntar: em que medida os modelos de formação continuada não intensificam a jornada de trabalho dos professores? Portanto, é 
urgente discutir os entraves para uma boa formação inicial e as possibilidades e impossibilidades de formação continuada, considerando as condições de trabalho a que os professores são submetidos, bem como de sua extensiva jornada laboral, vale salientar.

Embora a referência seja o conceito de alienação elaborado por Marx, parte-se da premissa de que não é possível a aproximação direta entre esse conceito, e seus desdobramentos, como a criação de valor, e o trabalho docente. Nesse sentido, vale destacar que o filósofo alemão elaborou esse conceito com base na estrutura (relações de produção), assim como das análises que realizou sobre as condições de trabalho e de sobrevivência do operariado da Inglaterra no século XIX, local em que se envolveu ativamente nos movimentos trabalhistas daquele período e na sua produção intelectual. Portanto, deve-se examinar a realidade dos professores da escola pública e identificar as condições que conduzem à alienação, considerando em parte os fundamentos teóricos de Marx, mas sobretudo a alienação na sua forma mais ampliada, que inexoravelmente abrange aspectos de ordem econômica, social, cultural, psicológica e educacional.

Daí ser possível recorrer a outros autores, como, por exemplo, Antunes e Alves (2004), que, ao discutir o trabalho no século XXI, afirmam que a venda da força de trabalho não se restringe aos trabalhadores manuais diretos. Incorpora também a totalidade do trabalho social, a totalidade do trabalho coletivo, que vende sua força de trabalho como mercadoria em troca de salário. Quer dizer, o capital incorpora o núcleo central do proletariado industrial, os trabalhadores produtivos que participam diretamente do processo de criação de mais-valia e da valorização do capital e "abrange também os trabalhadores improdutivos, cujos trabalhos não criam diretamente mais-valia, uma vez que são utilizados como serviço, seja para uso público, como os serviços públicos, seja para uso capitalista" (Antunes e Alves, 2004, p. 342, grifos dos autores). O que parece evidente é que, enquanto os indivíduos se mantiverem aprisionados em atividades nas quais não seja possível a autonomia e nem o desenvolvimento de faculdades e habilidades voltadas para a realização individual, permanecerá a necessidade da luta política contra a alienação.

Assim, um estudo sobre as condições de trabalho de um grupo de professoras da rede pública estadual paulista e também de como compreendem os problemas e propostas educacionais e de organização do ensino pode contribuir para colocar em evidência os fatores que impedem a escola pública de oferecer uma educação de qualidade para seus alunos. Partindo do suposto de que a alienação se espraia em todos os campos de atividade na sociedade capitalista, pode-se afirmar que os professores estão envolvidos nesse processo, permitindo-se então atentar para "a perda de sua própria unidade: trabalho e lazer, meios e fins, vida pública e vida privada, entre outras formas de disjunção dos elementos de unidade presentes na sociedade do trabalho" (Antunes e Alves, 2004, p.347). Ora, se os professores 
sofrem com essa situação, há claros indícios de que o seu trabalho pedagógico fica comprometido no cotidiano de suas práticas.

Frente às delineações iniciais apresentadas, o foco aqui é verificar se a condição funcional de um grupo de 37 professoras atuantes no ciclo I do ensino fundamental da rede pública estadual paulista interfere nas percepções que possuem da referida rede de ensino, mais precisamente, identificar se a condição funcional infere na capacidade de crítica ou conformismo ao disposto.

\section{Método e procedimento de pesquisa}

Como procedimento de pesquisa, optou-se pela elaboração de um questionário e sua aplicação em um grupo de professoras do ciclo I do ensino fundamental. Ele foi composto por questões fechadas e abertas, com as quais se objetivou averiguar as respostas que certos indivíduos dão a determinado questionamento (Selltiz,et al., 1974). A escolha do questionário como técnica de coleta de informações está associada à complexidade de algumas questões que, por conta disso, demandaram um esforço de pensamento e reflexão dos indivíduos. E é justamente em decorrência da possibilidade dos sujeitos pensarem sobre certos temas que se entendeu razoável a escolha dessa técnica, o que permitiu conhecer como as professoras se posicionam sobre tais temas. Ao apontar as vantagens do questionário, Selltizet al. (1974, p.17) afirmam que "este poderá exercer menos pressão sobre o respondente para que dê uma resposta imediata".

Ressalte-se que antes da aplicação às professoras que compuseram a amostra, foi realizado um pré-teste para o aperfeiçoamento do instrumento com três outros professores, o que permitiu, posteriormente, realizar alguns ajustes no questionário.

\section{Seleção das escolas e das professoras para a composição da amostra}

A pesquisa foi realizada no município de Campinas (SP), em escolas da rede pública estadual. Diante da impossibilidade de investigar os professores presentes em todas as escolas do município, alguns critérios foram adotados para a seleção dos indivíduos que fizeram parte da amostra. O primeiro deles visou à delimitação da região e do ciclo de ensino no qual os professores atuam.

A seleção das escolas foi baseada na divisão regional do município de Campinas e na divisão das Diretorias de Ensino. Geograficamente, Campinas é dividida em seis 
regiões: Central, Norte, Leste, Sul, Oeste e Noroeste. No que diz respeito às escolas públicas estaduais, o município possui duas Diretorias de ensino (Leste e Oeste). Um fato a ser destacado é que, no processo de divisão das escolas entre as duas diretorias, não foi tomado como critério nenhuma delimitação geográfica, o que ocasionou a distribuição das escolas de quase todas as regiões de Campinas em ambas as Diretorias. Embora essa distribuição não tenha sido feita em função da localidade em que estão, observa-se uma particularidade na Região Noroeste: suas escolas pertencem à Diretoria de Ensino Região Campinas Oeste (Derco). Por conta disso, essa diretoria foi selecionada para a pesquisa. A definição não ocorreu porque diretoria de ensino e região da cidade coincidem quando se olha para a localização das escolas, mas em razão da diversidade encontrada. A Derco é composta por 94 escolas, sendo 84 localizadas no próprio município de Campinas, sete em Valinhos e três em Vinhedo. As escolas de Vinhedo e Valinhos possuem a peculiaridade de atenderem somente ao ciclo II do ensino fundamental ( $6^{\circ}$ ao $9^{\circ}$ ano) e ensino médio, cabendo à Rede Municipal de Educação desses municípios o oferecimento do ciclo I (antiga $1^{\text {a }}$ a $4^{\text {a }}$ série, atualmente $1^{\circ}$ ao $5^{\circ}$ ano). Esse fato exclui tais escolas porque - como será justificado mais adiante - foram investigados somente professores atuantes no ciclo I. Dessa forma, só as unidades escolares localizadas no município de Campinas constituíram a base para a seleção das escolas e, por conseguinte, dos sujeitos investigados. Das 84 escolas da Derco situadas em Campinas, 55 atendem ao ciclo I do ensino fundamental.

Tendo em vista o grande número de escolas (55), optou-se por investigar sujeitos de todas as escolas pertencentes à Derco e situadas na Região Noroeste de Campinas. Tal escolha está associada ao fato de que essas escolas, além de pertencerem à mesma Diretoria de Ensino - o que não ocorreria se a investigação ocorresse em alguma outra região -, também possuem a peculiaridade de estarem localizadas em uma região caracterizada como periférica, seja pela distância da região central, seja pelas condições socioeconômicas da população atendida. Sendo assim, as professoras que fizeram parte da amostra atuam na região Noroeste de Campinas, que possui 16 escolas da rede pública estadual. Deste total, 10 atendem ao ciclo I do ensino fundamental.

\section{Procedimentos de coleta de dados}

Para a aplicação do questionário, o pesquisador foi à Derco, apresentou o questionário e o Termo de Consentimento Livre e Esclarecido e, posteriormente, solicitou ao Dirigente de Ensino uma Carta de Apresentação para ser levada às escolas. Em seguida, foi até as unidades educacionais selecionadas com o intuito de agendar um dia para visita no Horário de Trabalho Pedagógico Coletivo (Htpc) a fim de realizar, nesse momento, a coleta dos dados. 
Ressalte-se que, quando da aplicação do questionário, o pesquisador esteve junto às professoras a fim de elucidar possíveis dúvidas referentes ao entendimento do enunciado das questões. Dessa forma, o questionário foi aplicado - entre os meses de setembro e novembro de 2012 -, nas dez escolas, para as professoras que, após o pesquisador apresentar a pesquisa, aceitaram participar. O fato de estar junto aos sujeitos de pesquisa não implicou nenhum prejuízo para a confiabilidade das informações, uma vez que a intervenção ocorreu somente com o intuito de esclarecer dúvidas a respeito do questionário e nunca emitir opiniões sobre as temáticas apresentadas.

Para garantir os princípios éticos que envolvem a pesquisa com seres humanos, o pesquisador entregou aos sujeitos, e leu com eles, o Termo de Consentimento Livre e Esclarecido. Assim, a aplicação do questionário só ocorreu após autorização e consentimento por escrito das professoras envolvidas. Além disso, o pesquisador assumiu o compromisso de manter absoluto e total sigilo e confidencialidade em relação à identidade dos sujeitos e das informações fornecidas.

Um fator a ser ressaltado diz respeito à dificuldade de acesso às unidades escolares e, por conseguinte, de adesão das professoras. Os Htpcs nas escolas onde estão situados os sujeitos que fizeram parte da amostra ocorrem em dois dias da semana e, em alguns casos, o grupo de professoras é dividido e as reuniões acontecem em dias distintos. Por conta disso - e devido à dispensa das professoras ter sido autorizada pelo dirigente de ensino somente em uma reunião de Htpc -, a apresentação do questionário foi feita a 73 professoras. Desse total, 37 aderiram à pesquisa.

\section{Relação entre condição funcional e percepção das condições de trabalho}

O ponto de partida é o postulado de que o trabalhador, de forma geral, sofre determinações "do" e "pelo" trabalho, o mesmo ocorrendo com os trabalhadores da educação. Marx (2006, p.67), ao se referir sobre a relação entre o trabalhador e suas condições de trabalho, enfatiza que "o trabalhador não tem apenas de lutar pelos seus meios físicos de subsistência; deve ainda lutar para alcançar trabalho, isto é, pela possibilidade e pelos meios de realizar sua atividade". Embora a análise do autor tivesse como foco outro contexto histórico e a relação contraditória existente na indústria entre trabalhador e capitalista, fatores como a luta pela subsistência e para realizar sua atividade, destacadas por ele podem contribuir para o entendimento da situação vivida por professores, uma vez que, em determinadas situações os docentes permanecem em uma posição de insegurança por vários anos da carreira, o que, por conseguinte, acaba enfraquecendo a capacidade de se opor à realidade objetiva. 
Nessa linha de raciocínio sobre a relação dos indivíduos com o sistema, o foco a ser verificado aqui é a relação entre condição funcional de um grupo de professoras e a percepção que possuem sobre o lócus de trabalho que estão inseridas, emergindo o seguinte questionamento: as condições de trabalho enfrentadas desencadeiam alguns mecanismos para a submissão do indivíduo ao todo?

Tendo como premissa responder a tal questionamento, apresenta-se inicialmente, na tabela 1, a situação funcional das professoras pesquisadas. No que diz respeito à situação funcional das professoras, destaca-se que a maior parte é Ocupante de Função Atividade (OFA), isto é, sem estabilidade no emprego. Assim, um número significativo de professoras exerce o magistério sem possuir cargo pois não são concursadas.

Tabela 1: Situação funcional das professoras da amostra na rede pública estadual paulista

\begin{tabular}{l|l|l|}
\hline Condição funcional na SEE/SP & Qtde. & Proporção \\
\hline Efetiva & 8 & 0.22 \\
OFA & 26 & 0.70 \\
Estável & 3 & 0.08 \\
\hline TOTAL & $\mathbf{3 7}$ & $\mathbf{1 . 0 0}$ \\
\hline
\end{tabular}

Fonte: Dados da pesquisa

A situação funcional das professoras pode determinar a instabilidade na carreira, e tal situação pode interferir na percepção dos indivíduos sobre o sistema em que estão inseridos. Tendo em vista essa linha de reflexão, na tabela 2, realizouse o cruzamento entre a situação funcional das professoras com a percepção que possuem sobre a qualidade da educação na rede estadual paulista.

Tabela 2: Relação entre situação funcional e opinião sobre a qualidade da educação na rede estadual paulista

\begin{tabular}{l|l|l|l|l|l|}
\hline $\begin{array}{l}\text { A qualidade da educação } \\
\text { na rede estadual } \\
\text { paulista está }\end{array}$ & $\begin{array}{l}\text { Não } \\
\text { respondeu }\end{array}$ & Boa & Regular & Ruim & Total \\
$\begin{array}{l}\text { Situação funcional } \\
\text { das professoras }\end{array}$ & - & - & 4 & 4 & $\mathbf{8}$ \\
\hline Efetiva & - & 3 & 4 & 19 & $\mathbf{2 6}$ \\
\hline OFA & 1 & 1 & 1 & - & $\mathbf{3}$ \\
\hline Estável & $\mathbf{1}$ & $\mathbf{4}$ & $\mathbf{9}$ & $\mathbf{2 3}$ & $\mathbf{3 7}$ \\
\hline TOTAL & & & & \\
\hline
\end{tabular}

Fonte: Dados da pesquisa 
Destaque-se que das oito professoras efetivas, nenhuma afirmou que a educação na rede estadual está "boa" - quatro indicaram ser regular e quatro indicaram ser ruim. Em contrapartida, quatro professoras afirmaram ser "boa" a educação na rede estadual paulista. No entanto, nota-se que nenhuma delas é efetiva. Depreendese dos dados apresentados que existe relação entre instabilidade funcional e posicionamento menos crítico; de modo inverso, a estabilidade está associada a maior possibilidade de crítica.

Tendo em vista aprofundar como se consubstancia a condição funcional com a percepção das professoras sobre o trabalho e, especificamente com as políticas educacionais oficiais, realizou-se o cruzamento entre a condição funcional das professoras e a opinião que expressam especificamente sobre a organização do ensino em ciclos com progressão continuada, política que foi implantada na rede pública estadual paulista no ano de 1998. Estudiosas dessa temática, Dias-da-Silva; Lourencetti (2002, p. 23) enfatizam que a implantação da organização do ensino em ciclos com progressão continuada foi "certamente o período de maior efervescência nas escolas públicas paulistas nos últimos anos", ou seja, trata-se da reforma que mais impactou o funcionamento das escolas. O resultado das percepções das professoras sobre a referida política educacional está expresso na tabela 3.

Tabela 3 - Relação entre situação funcional e opinião sobre a organização do ensino em ciclos com progressão continuada

\begin{tabular}{|c|c|c|c|c|c|c|c|}
\hline Situação funcional das & Efetivá & & OFA & & Estáve & & \\
\hline $\begin{array}{l}\text { A organização do ensino } \\
\text { em ciclos com progressão } \\
\text { continuada é: }\end{array}$ & Freq. & Prop. & Freq. & Prop. & Freq. & Prop. & Total \\
\hline Boa & 1 & 0.03 & 7 & 0.19 & 2 & 0.05 & 10 \\
\hline Ruim & 7 & 0.19 & 19 & 0.51 & 1 & 0.03 & 27 \\
\hline TOTAL & 8 & 0.22 & 26 & 0.70 & 3 & 0.08 & 37 \\
\hline
\end{tabular}

Fonte: Dados da pesquisa

Os dados ratificam a associação entre situação funcional e concepções mais ou menos críticas das professoras, haja vista que das oito professoras efetivas, sete consideram como ruim a organização do ensino em vigor. Dessa forma, tanto a opinião sobre a qualidade da educação - tabela 2 -, quanto a opinião sobre a organização do ensino parecem ser influenciadas pela situação funcional das professoras. Em outros termos, pode-se apontar que as condições objetivas nesse caso, a estabilidade ou instabilidade funcional - interferem na percepção e na tomada de posição diante das políticas educacionais e sua efetivação na escola. 
Ao discorrer sobre a relação do indivíduo com a totalidade, Adorno (1983, p.128) assinala que "a subjetividade pensante é o que não se pode integrar no círculo de tarefas heteronomamente imposto a partir de cima". Se as ponderações de Adorno apontam que a independência do pensamento é resguardada somente com a não integração do sujeito àquilo que é externo, pode-se considerar que a situação funcional, que impõe maior fragilidade ao professor, implica maiores chances de aceitação acrítica do que é imposto pelos órgãos superiores do sistema educacional. Não se trata de dizer que as professoras efetivas são imunes às influências do sistema, mas, de acordo com os dados obtidos na pesquisa, pode-se inferir que há nas respostas proferidas pelas professoras não efetivas uma maior incidência de conformidade com aquilo que se estabelece desde instâncias superiores da SEE/ SP. Em síntese, a condição funcional das professoras investigadas define diferentes perfis profissionais no que se refere à percepção de sua atividade profissional, bem como das determinações que emanam da administração dessa rede de ensino, incluindo os aspectos pedagógicos, que são retratados a seguir.

No que tange aos aspectos pedagógicos da docência, foi aplicada uma questão que teve como objetivo levantar informações sobre a relação que as professoras estabelecem com seus superiores diretos (coordenação pedagógica e direção). O foco recaiu sobre os nexos entre política educacional, gestão escolar e docência, considerando a gestão escolar como a instância representante das demandas oficiais, na qual, cruzou-se a condição funcional das professoras com a avaliação que fazem dos gestores. 
Tabela 4: Relação entre condição funcional e a avaliação que fazem as professoras da coordenação pedagógica e da direção

\begin{tabular}{|c|c|c|c|c|}
\hline $\begin{array}{l}\text { O apoio pedagógico proporcionado } \\
\text { pela direção e coordenação da escola é }\end{array}$ & Efetiva & OFA & Estável & Total \\
\hline Não respondeu. & - & 1 & - & 1 \\
\hline $\begin{array}{l}\text { Excelente, pois oferecem total apoio } \\
\text { para o desenvolvimento de meu trabalho. }\end{array}$ & - & 9 & - & 9 \\
\hline $\begin{array}{l}\text { Muito bom, pois sempre se esforçam } \\
\text { para dar o suporte para o } \\
\text { desenvolvimento de meu trabalho. }\end{array}$ & - & 4 & - & 4 \\
\hline $\begin{array}{l}\text { Bom, pois além de auxiliarem no } \\
\text { entendimento das propostas da } \\
\text { Secretaria da Educação, } \\
\text { sempre fazem cobranças e, por conta } \\
\text { disso, acabam nos motivando } \\
\text { a desenvolver um trabalho de qualidade. }\end{array}$ & - & 10 & 1 & 11 \\
\hline $\begin{array}{l}\text { Regular, pois preocupam-se muito } \\
\text { com questões burocráticas e esquecem } \\
\text { de dar atenção às questões pedagógicas, } \\
\text { aquelas voltadas ao dia a dia e à sala de aula. }\end{array}$ & 7 & 2 & 1 & 10 \\
\hline $\begin{array}{l}\text { Ruim, pois apenas cobram os resultados } \\
\text { de aprendizagem e não nos auxiliam } \\
\text { quando são procurados. }\end{array}$ & - & - & - & - \\
\hline $\begin{array}{l}\text { Muito ruim, pois apenas reproduzem } \\
\text { o discurso da Secretaria da Educação } \\
\text { e nos cobram a fazer o disposto oficialmente. }\end{array}$ & 1 & - & 1 & 2 \\
\hline TOTAL & 8 & 26 & 3 & 37 \\
\hline
\end{tabular}

Fonte: Dados da pesquisa

O que chama a atenção no cruzamento de dados é que das oito professoras efetivas, sete afirmaram que o apoio dos superiores imediatos é regular e uma que é muito ruim, enquanto que, das 26 professoras OFA, 23 apontaram que o apoio dos superiores imediatos é bom, muito bom ou excelente. Portanto, as professoras 
com maior estabilidade são mais críticas em relação aos superiores imediatos. As professoras OFA demonstram o contrário, talvez em decorrência das condições aviltantes a que são submetidas, principalmente nos momentos de atribuição de aulas e os locais destas no ano seguinte, pois além das constantes mudanças de ano para ano, realizadas pela SEE/SP, na forma de atribuir aulas para os não efetivos; há ainda, a submissão à prova anual classificatória, que acontece desde 2009, como parte do processo seletivo para atribuição de aulas.

Essa situação sozinha não explica o posicionamento das professoras pesquisadas, mas pode fornecer pistas sobre a maneira como um contingente importante de professores exerce sua atividade profissional.

Se a condição funcional está associada ao modo como os professores lidam com seus superiores, isso ocorre porque é impossível isolar os indivíduos dos determinantes sociais, pois, como apontado por Horkheimer e Adorno (1973, p.20), "o indivíduo não passa de uma abstração, se o tirarmos das suas determinações sociais". Embora a ponderação dos autores se referisse a outro contexto, não se pode desprezar o fato de que as professoras pesquisadas demonstram que o vivido objetivamente pode interferir nos posicionamentos assumidos. Tudo isso permite afirmar que a qualificação da prática do professor passa pela melhoria das condições de trabalho no magistério, tais como a eliminação do maior número possível de professores temporários, valorização pecuniária dos ganhos recebidos, redução do contingente de alunos por sala de aula, formação continuada de qualidade, entre outras.

Foi identificada a valorização dos superiores imediatos por auxiliarem em questões voltadas ao dia a dia escolar e, também, a tendência à fragilização dos indivíduos como resultado das condições vividas na docência. Do mesmo modo, identificouse a percepção das professoras no que tange às condições estruturais para desenvolverem seu trabalho.

Nessa linha de discussão, realizou-se o cruzamento da percepção que possuem das condições de trabalho com a condição funcional, como disposto na tabela a seguir. 
Tabela 5: Relação entre condição funcional das professoras e a percepção que possuem das condições físicas da escola

\section{Condição Funcional na SEE/SP}

As condições físicas da escola estadual em que atua são: Ruins e me impedem de desenvolver um trabalho de qualidade.

Regulares, pois embora tenha uma estrutura que permita trabalhar, necessita melhorar alguns aspectos para um melhor desenvolvimento da escola.

\begin{tabular}{l|l|l|l|l} 
Boas, pois permite realizar meu trabalho. & - & 23 & - & 23 \\
\hline $\begin{array}{l}\text { Ótimas, pois a estrutura oferecida, } \\
\text { Inclusive, me ajuda no desenvolvimento } \\
\text { de minhas práticas cotidianas na escola. }\end{array}$ & - & 2 & - & 2 \\
\hline TOTAL & 8 & 26 & 3 & 37 \\
\hline
\end{tabular}

Fonte: Dados da pesquisa

A tabela 5 mostra dados substantivos sobre a relação entre condição funcional e percepção das condições de trabalho. Verifica-se certa tendência de aceitação das condições físicas da escola pelas professoras OFA - 25 entre 26 consideram boas e ótimas essas condições. De outra parte, as professoras efetivas e estáveis avaliam de forma mais rigorosa a estrutura física da escola - todas as 11 consideram-na regular ou ruim. Esse fato permite identificar uma associação entre condição funcional e a percepção das condições físicas da escola e, mais precisamente, possibilita inferir que a percepção das professoras sobre a estrutura do local onde atuam está, de algum modo, vinculada ao grau de estabilidade: verificou-se maior tendência de crítica por parte das professoras efetivas e estáveis. Marcuse (1967, p.28), ao discutir as novas formas de controle, aponta que "não é fator decisivo para a determinação do grau de liberdade humana, mas [condiciona] o que pode ser escolhido e o que é escolhido pelo indivíduo". Essa ponderação do autor sugere que a forma como estabelecem suas percepções está associada às imposições oriundas das condições objetivas a que se submetem, neste caso, à situação funcional.

Assim, parece importante saber qual a situação funcional dessas professoras em 
relação à posição que assumem frente ao material didático oferecido nas escolas, tal como disposto na tabela a seguir.

Tabela 6: Relação entre condição funcional das professoras e a percepção que possuem dos materiais pedagógicos disponíveis nas escolas

Condição Funcional na SEE/SP

Em relação ao material

pedagógico disponível você considera:

Inadequado, pois faltam materiais.

\begin{tabular}{|c|c|c|c|c|}
\hline Inadequado, pois faltam materiais. & 3 & - & - & 3 \\
\hline Suficiente para desenvolver meu trabalho. & - & 6 & 1 & 7 \\
\hline $\begin{array}{l}\text { Adequado, pois tenho acesso a todo tipo } \\
\text { de material que solicito. }\end{array}$ & 1 & 20 & 2 & 23 \\
\hline $\begin{array}{l}\text { Regular, pois nem sempre há } \\
\text { disponibilidade destes materiais } \\
\text { na escola. }\end{array}$ & 3 & 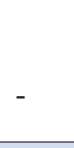 & - & 3 \\
\hline $\begin{array}{l}\text { Insatisfatório, pois alguns materiais que } \\
\text { a escola possui nem sempre os professores } \\
\text { têm acesso. }\end{array}$ & 1 & - & - & 1 \\
\hline TOTAL & 8 & 26 & 3 & 37 \\
\hline
\end{tabular}

Fonte: Dados da pesquisa

A tabela 6 mostra que sete professoras possuem percepção negativa quanto aos materiais disponíveis. Isso pode estar associado à condição funcional: sete de oito professoras efetivas reconhecem, com maior ou menor intensidade (inadequados, insatisfatórios ou em pouca quantidade), a insuficiência do material didático disponível e somente uma professora efetiva considerou adequada a disponibilidade de materiais. Esse dado está em consonância com a interpretação já ensaiada anteriormente: a maior resistência ao disposto pelas políticas educacionais e às regulamentações impostas pela SEE/SP é apresentada pelas professoras efetivas, uma vez que se situam em condição funcional com estabilidade de emprego. 


\section{Considerações Finais}

O presente estudo teve como objetivo verificar se a condição funcional interfere na percepção que professoras atuantes no ciclo I do ensino fundamental da rede pública estadual paulista possuem das condições de trabalho. Diante dos dados obtidos pode-se avaliar que as professoras OFA tendem a apresentar maior conformidade com as determinações emanadas pela administração da rede pública estadual de São Paulo. Tal assertiva é ratificada nas opiniões apresentadas aqui sobre a qualidade da educação na rede estadual, naquela relativa à organização do ensino em ciclos com progressão continuada, sobre a coordenação pedagógica e a direção da escola e, por fim, sobre as condições físicas da escola. Se o que expressam acerca dos fatores destacados é influenciado pela condição funcional, pode-se argumentar que, embora pertençam à mesma rede (SEE/SP), as imposições advindas das políticas educacionais atingem de maneira diversa as professoras. Em outros termos, pode-se apontar que as opiniões das professoras OFA também expressam a fragilidade que a condição funcional lhes impõe. Para interpretar a relação indivíduo e sociedade recorre-se a Marcuse (1967). Para o autor as respostas dos indivíduos só podem ser dadas

(...) pelos próprios indivíduos, mas apenas em última análise; isto é, se e quando eles estiverem livres para dar a sua própria resposta. Enquanto eles forem mantidos incapazes de ser autônomos, enquanto forem doutrinados e manipulados, a resposta que derem não poderá ser tomada por sua (Marcuse, 1967, p.27).

As ponderações do autor, ao serem confrontadas com os dados empíricos, permitem especular que, em decorrência da instabilidade vivida no trabalho, as professoras podem apresentar pouca capacidade de posicionamento crítico. Ainda que o próprio Marcuse (1967) sublinhe a necessidade da interpretação dialética para as escolhas que os indivíduos são capazes de fazer, destaca-se o seguinte posicionamento do autor: "sugiro a expressão 'escolha determinada' a fim de acentuar a invasão da liberdade na necessidade histórica; a expressão nada mais faz do que condensar a proposição de que os homens fazem sua própria história, mas fazem-na sob determinadas condições" (p.206); ainda assim, percebem-se as condições pelas quais as professoras investigadas estão submetidas, e que, consequentemente, determinam as possibilidades de crítica e suas percepções sobre a escola e a docência.

O que chama a atenção, no entanto, é certa consonância de que os professores devem ser críticos, assim como instigarem os alunos a serem críticos, emergindo daí certa contradição, pois estes profissionais são determinados por instâncias intermediárias - no caso aqui investigado, a condição funcional - que lhes imputam a possibilidade de crítica. Como sustenta Marcuse (1967), o indivíduo se vê reduzido diante do poder da sociedade e, portanto, não consegue refletir sobre ela. E sem tal 
capacidade de reflexão sobre o que diz respeito ao seu próprio trabalho, torna-se questionável como os indivíduos poderão ser críticos às demais demandas sociais, visto que, no caso da docência torna-se ainda mais complexo devido à função social que o professor exerce na formação das novas gerações.

Em decorrência dos resultados colididos, aponta-se que um importante caminho na luta pela melhoria da qualidade da educação oferecida na escola pública está associado à melhora nas condições de trabalho dos professores.

\section{Referências bibliográficas}

ADORNO, Theodor. Mínima moralia. Lisboa. Editora: edições 70, 1983.

ANTUNES, Ricardo; ALVES, Giovani. As mutações no mundo do trabalho na era da mundialização do capital. Educação \& Sociedade, Campinas, v. 25, n. 87, p. 335351, mai./ago, 2004.

BARBOSA, Andreza. Os salários dos professores brasileiros: implicações para o trabalho docente. Araraquara, 2011. Tese de doutorado. UNESP.

CROCHÍK, José Leon. Notas sobre trabalho e sacrifício. Trabalho, Educação e Saúde,1(1):61-73, 2003.

DIAS-DA-SILVA, Maria HelenaFrem; LOURENCETTI, Gisela do Carmo. A voz dos professores e algumas reformas educacionais nas séries finais do ensino fundamental: desencontros ou impasses? In: SAMPAIO, Maria das Mercês Ferreira (org). O cotidiano escolar frente às políticas educacionais - $1^{\text {a }}$ edição, 2002. Araraquara: JM Editora.

FREUD, Sigmund. O mal-estar na civilização, novas conferências introdutórias à psicanálise e outros textos(1930-1936) / Sigmund Freud. São Paulo: Companhia das Letras, 2010.

HORKHEIMER, Max; ADORNO, Theodor. Temas básicos de Sociologia. São Paulo: Cultrix, 1973.

HORKHEIMER, Max; ADORNO, Theodor. Dialética do Esclarecimento. Rio de Janeiro: Jorge Zahar, 1985.

MAAR, Wofgang Leo. A Dialética da Centralidade do Trabalho. Ciência e Cultura 
(SBPC), São Paulo, v. 58, p. 26-28. 2006.

MARCUSE, Herbert. A ideologia da sociedade industrial. Rio de Janeiro: Zahar Editores, 1967.

MARCUSE, Herbert. Eros e Civilização: uma interpretação filosófica do pensamento de Freud. Rio de Janeiro: Zahar Editores, 1969.

MARX, Karl. O capital. São Paulo: Abril Cultural, 1983.

MARX, KarlManuscritos econômicos-filosóficos. São Paulo: Editora Martin Claret, 2006.

MARX, Karl; ENGELS, Friedrich. A ideologia alemã: teses sobre Feuerbach. São Paulo: Editora Moraes, 1994.

OLIVEIRA, Dalila. Andrade. A Reestruturação do Trabalho Docente: precarização e flexibilização.Educação e Sociedade, Campinas - SP, v. 25, n.89, p. 1127-1144. 2004.

RESENDE, Anita Cristina de Azevedo.Da relação indivíduo-sociedade. Educativa (UCG), v. 10, p. 29-46, 2007.

SÁNCHEZ VÁSQUEZ, Adolfo. Filosofia da práxis. Rio de Janeiro. Paz e Terra, 1977.

SELLTIZ, Claire et. al. Métodos de pesquisa nas relações sociais. São Paulo: EPU, 1974.

\section{Recebido em 15 de outubro de 2015}

Aprovado em 28 de setembro de 2016

Anoel Fernandes é doutor em Educação pela PUC/SP (2014). Tem experiência na área de Educação, com ênfase em Pedagogia e Educação Física, condições de trabalho e formação de professores. Email: anoelfernandes@ig.com.br

Edson Segamarchi dos Santos é Doutor em Educação pela Pontifícia Universidade Católica de São Paulo (PUC-SP). Atua como pesquisador no Grupo de pesquisa GEPLAGE: Grupo de Estudos e Pesquisas Estado, Política, Planejamento, Avaliação e Gestão da Educação da Universidade Federal de São Carlos (Campus Sorocaba). Email: edsega1@ig.com.br 